\title{
Transcultural adaptation and validation of the Conditions of Work Effectiveness - Questionnaire-II instrument
}

\author{
Elizabeth Bernardino ${ }^{1}$ \\ Ana Maria Dyniewicz ${ }^{2}$ \\ Kaoana Lima Botto Carvalho ${ }^{3}$ \\ Luísa Canestraro Kalinowski ${ }^{4}$ \\ Wagner Hugo Bonat ${ }^{5}$
}

\begin{abstract}
Objective: This study aims at translating and validating the content of the instrument Conditions of Work Effectiveness - Questionnaire-II (CWEQ-II), developed by Laschinger, Finegan, Shamian and Wilk, modified from the original CWEQ for the Brazilian culture. Method: the methodological procedure consisted of the stages of translation of the instrument into the Portuguese language; back-translation; semantic, idiomatic and cultural equivalence and tests of the final version. The instrument in the Portuguese version was applied to a group of 40 nurses in two hospitals. Results: the data resulted in a Cronbach's Alpha of 0.86 for the first hospital and 0.88 for the second one. The results of the factorial analysis are considered sufficiently satisfactory. Conclusion: It is to conclude that the instrument can be used in Brazil.
\end{abstract}

Descriptors: Efficiency; Work; Validation Studies; Nursing.

\footnotetext{
${ }^{1} \mathrm{PhD}$, Adjunct Professor, Departamento de Enfermagem, Universidade Federal do Paraná, Curitiba, PR, Brazil. ${ }^{2} \mathrm{PhD}$, Retired Professor, Departamento de Enfermagem, Universidade Federal do Paraná, Curitiba, PR, Brazil.

${ }^{3}$ Master's student, Departamento de Enfermagem, Universidade Federal do Paraná, Curitiba, PR, Brazil.

${ }^{4}$ Master's student, Departamento de Enfermagem, Universidade Federal do Paraná, Curitiba, PR, Brazil. Scholarship holder from Coordenação de Aperfeiçoamento de Pessoal de Nível Superior (CAPES).

${ }^{5}$ MSc, Assistant Professor, Departamento de Estatística, Universidade Federal do Paraná, Curitiba, PR, Brazil.
}

Correspondencia:

Elizabeth Bernardino

Universidade Federal do Paraná. Departamento de Enfermagem

Av. Lothário Meisnnern, 632

Bloco Didático II

Jardim Botânico

CEP: 80210-170, Curitiba, PR, Brasil

E-mail: elizaber@ufpr.br 


\section{Introduction}

Empowerment is a polysemic concept that has been used in an increasing form, mainly as from the 90's. The term stems from the English word empowerment. This concept takes into account the experience in distinct fields of knowledge, having its roots in the fights for the civil laws, in the feminist movement and the ideology of "social action", present in the decade of the 50's. In the 70 's, it was influenced by the self-help movements, and, in the 80 's, by communitarian psychology. In the decade of the 90's, it received influx from movements that aimed to affirm the right of the citizens regarding health care, health education and physical environment ${ }^{(1)}$.

There are two distinct notions of empowerment: psychological and the communitarian one. In the first one, there is the feeling of greater control of the own life when belonging to distinct groups; an individualistic philosophical perspective that ignores the influence of social and structural factors; and a vision that fragments the human condition when detaching the human behavior from the sociopolitical context in which they are inserted ${ }^{(1)}$

In the communitarian notion, the power works as conflicting category, distributed in unequal form by the society, that is constituted of different interest groups which possess differentiated levels of power and control of the resources. This makes what processes of empowerment many times imply, the redistribution of power and the resistance of those who lose it. In this form, the practices of health education, organization management, reorganization of the work process in health and the strategies of communitarian participation should be rethought ${ }^{(1)}$.

Consequently, the empowerment has a relation with the increase of power, personal autonomy in interpersonal and institutional relations, mainly in relations of oppression, discrimination and social domination. In special, the empowerment is related to local actions for the formation of political alliances that increase the debate about oppression in terms of contextualizing, favoring its understanding as historical, structural and political phenomenon(2).

Power within organizations derive from structural conditions and not from personal characteristics or the effects of socialization, it is relative and determines the behavior and the perception of impotence of the people in different hierarchical levels ${ }^{(3)}$. The conscience and behavior formed through the held position in an organization demonstrate how men and women are products of their circumstances. In bureaucratic administrations, power and leadership derive from a position and people must work with and through others in order to have this power(4).

This model is still effective among nurses in Brazil and, even so they are the biggest in number among health professionals, the organizational support that they are given is still low ${ }^{(3)}$. The power of the nurses is related more to the professional power ${ }^{(5)}$ in detriment of the structural one, even with the increase of their scope of functions in recent years ${ }^{(6-7)}$

The model of organizational empowerment ${ }^{(4)}$ is potentially used by administrative nurses with respect to professional autonomy. If the work relations will have support in studies on empowerment, programs to correct the traditional structures can be created, thus getting solid results.

The Conditions for Work Effectiveness Questionnaire (CWEQ) was based on the structural power theory by Kanter (1977). A first version of the theory, CWEQ-I, was adapted for nursing(8) in 1986. In 2001(9), an extended model of the structural power theory by Kanter was tested, having as base for the analysis of variables The Conditions of Work Effectiveness Questionnaire - CWEQ-I and the Psychological Empowerment (Questionnaire: Job Content Questionnaire and Global Satisfaction Scale). The extended model was applied in a random sample of 404 Canadian nurses who showed a good adjustment of the model. The results revealed that the structural strengthening felt by the interviewed nurses resulted in bigger levels of psychological qualification. These intense feelings of psychological qualification are strongly influenced by the tension and satisfaction at work, however the tension does not have a direct effect on the satisfaction. It is to conclude that the extended model of The Conditions of Work Effectiveness Questionnaire - CWEQ-II supplies a tool for the understanding of intervention mechanisms within the work conditions and the process of organizational qualification $^{(9)}$.

In light of the relevance of the subject for the profession and the inexistence of an instrument in Brazil that allows to measure the empowerment of nurses in health institutions, the CWEQ-II is another form to implement useful and important management measures by means of strategies that can reduce the tension and improve the satisfaction, having as consequence a better performance of the configurations in the work of nurses. The objective of this article was to accomplish the translation, the cultural adaptation and the validation 
of the contents of the Conditions of Work Effectiveness - Questionnaire-II (CWEQ-II), so that it can be used in Brazil.

\section{Method}

A methodological study of adaptation and validation of the subjective variable measurement tool of the instrument CWEQ-II for the Portuguese language was accomplished. This process was based on literature(10): a) translation of the original version of the instrument in English into the Portuguese language by two translators whose native language is Portuguese, thus resulting in two versions; b) individual evaluation by the researchers of the two versions; c) comparison of the two versions by two external researchers of this study for attainment of an only version in Portuguese; d) verification of the version in Portuguese by the researchers and translators, as for the detection of errors and divergent interpretations of items with ambiguous meanings in the original version; c) translation of the version in Portuguese into English (back-translation), accomplished by the researchers and two professors of nursing with fluency in English; d) comparison of the original version in English with the back-translation; e) evaluation of semantic, idiomatic, cultural and conceptual equivalences of the instrument for the final version in Portuguese, made by judges: two translators whose native language is English and two professors of nursing with fluency in English; f) definition of the final version on the basis of inexistence of divergences shown by the judges for the cultural

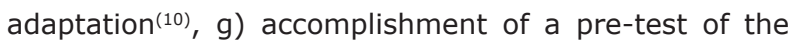
instrument with five members of a research group, which did not show any alteration of the final version of the instrument in Portuguese.

The instrument, in its final version, was composed by six components of structural empowerment: opportunity, information, support, resources, formal power and informal power, each one having three or four items that validate them. Furthermore there is the component of global empowerment, composed of two items that validate it, one on environment and the other one on workplace.

The six components of structural empowerment were named in the research as follows: opportunity (F1) with the 3 questions Q1, Q2 and Q3; information (F2) with the 3 questions Q1, Q2 and Q3; support (F3) with the 3 questions Q1, Q2 and Q3; resources (F4) with the 3 questions Q1, Q2 and Q3; formal power (F5) with the 3 questions Q1, Q2 and Q3; and informal power (F6) with the 4 questions Q1, Q2, Q3 and Q4, besides the two questions for measuring the component of global empowerment (D1 and D2), totalizing in 21 questions. Considering that each question (F1Q1, F1Q2, F1Q3...) was presented in the Likert scale, it resulted in a set of points that corresponds to the answers of the nurses of Hospital 1 and Hospital 2.

All the questions were answered based on an evaluation scale from 1 (or least positive) to 5 (or most positive) that follows the original in English, which means it suggests an increasing order of positive value in the options of the respondents. For the evaluation of the score, the highest achieved values in each of the 7 components of the questionnaire were taken into consideration.

The validation of the components of the questionnaire was accomplished with 40 nurses of two hospitals in Curitiba - Paraná, named Hospital 1 and Hospital 2. The percentage of interviewed nurses in Hospital 1 was $10 \%$ and in Hospital 2 it was $30 \%$. It is to distinguish, however, that it was intentional to have a random sample among nurses who were willing to participate in the study. There were determined as eligibility criteria: to be practical nurse in any unit of the hospital; to have been approved in a probatory test, then, with definitive employment bond in the institution and to accept participating voluntarily in the study. For identification of the respondents, the researchers had elaborated eight closed questions related to personal and professional data.

The project got the authorization of the Committee for Ethics in Research of the Hospital de Clinicas of the Federal University of Paraná, CAAE: 0302.0.208.00009. Following, contact with the directors of Nursing of the institutions was made, requesting authorization for development of the research. After the consent of the participating nurses, all signed the Term of Free and Clarified Assent.

The researchers and a Nursing academic delivered the nurses the questionnaire with guidelines and summoned the collection of the same. The data collection occurred between July and December 2009, at the proper workstation of the nurses.

\section{Data processing}

The data obtained from the instruments were transcribed in a spread sheet and for the statistic analysis the computational program $\mathrm{R}$ was used, that means Language and Environment for Statistical Computing. The identification data of the interviewees were processes by 
means of simple descriptive statistics and the items of the questionnaire were submitted to psychometric tests.

The Cronbach's Alpha was used to authenticate the internal consistency of the instrument. It is an index that assumes values between 0 and 1 and measures the homogeneity between the questions and all the correlations among the evaluated items. Its interpretation is that the closer to 1 , the Cronbach's Alpha makes the evaluation instrument more trustworthy(11-12). In this study, values above 0.80 were taken as reference, indicating high internal consistency, whereas values above 0.60 indicate intermediate consistency ${ }^{(13-14)}$.

A test was also used for the validation of the seven components of the questionnaire CWEQ-II, by means of factorial analysis. It is to point out that, for this analysis, a matrix of correlations of the polis-serial type was used, once a variable reply is of ordinal nature, what makes the Pearson coefficient of correlation inadequate. Moreover, for the estimation of the model the technique of main components was used contrary to the traditional method of Maximum Probability, that assumes Multivariable Normality of the answers. The posed tests in this study differ from the original, therefore the analyses were made through structural equations that would not be compatible with the objectives of this research.

\section{Results}

The results of the research were divided into two moments. The first one, with identification data and characteristics of the respondents of Hospital 1 and Hospital 2 (Table 1). Afterwards, psychometric tests were accomplished, and the version in Portuguese was named Conditions of Efficiency at Work-II (CET-II).

Table 1 - Identification data and characteristics of the interviewees, Curitiba, PR, Brazil, 2009

\begin{tabular}{|c|c|c|c|c|}
\hline \multirow{2}{*}{ Variables } & \multicolumn{2}{|c|}{ Hospital 1} & \multicolumn{2}{|c|}{ Hospital 2} \\
\hline & $\mathbf{F}$ & $\%$ & $\mathbf{F}$ & $\%$ \\
\hline \multicolumn{5}{|l|}{ Gender } \\
\hline Feminine & 20 & 100 & 17 & 85 \\
\hline Masculine & 0 & - & 3 & 15 \\
\hline \multicolumn{5}{|l|}{ Age (years) } \\
\hline 20 to 30 & 07 & 35 & 08 & 40 \\
\hline 31 to 40 & 08 & 40 & 01 & 05 \\
\hline 41 to 50 & 05 & 25 & 11 & 55 \\
\hline \multicolumn{5}{|l|}{ Marital Status } \\
\hline Single & 09 & 45 & 09 & 48 \\
\hline Married & 08 & 40 & 07 & 37 \\
\hline Cohabited & 02 & 10 & 02 & 10 \\
\hline Divorced & 01 & 5 & 01 & 5 \\
\hline
\end{tabular}

Table 1 - (continuation)

\begin{tabular}{|c|c|c|c|c|}
\hline \multirow{2}{*}{ Variables } & \multicolumn{2}{|c|}{ Hospital 1} & \multicolumn{2}{|c|}{ Hospital 2} \\
\hline & $\mathbf{F}$ & $\%$ & $\mathbf{F}$ & $\%$ \\
\hline \multicolumn{5}{|l|}{ Work duration (years) } \\
\hline$>1$ & 00 & - & 01 & 5 \\
\hline 1 to 4 & 05 & 25 & 05 & 25 \\
\hline 5 to 7 & 04 & 20 & 03 & 15 \\
\hline 8 to 10 & 03 & 15 & 04 & 20 \\
\hline 11 to 13 & 00 & - & 04 & 20 \\
\hline 14 to 16 & 04 & 20 & 02 & 10 \\
\hline 17 to 19 & 03 & 15 & 00 & - \\
\hline 20 to 22 & 01 & 5 & 01 & 5 \\
\hline \multicolumn{5}{|l|}{$\begin{array}{l}\text { Time in the current } \\
\text { position (years) }\end{array}$} \\
\hline 0 to 5 & 10 & 50 & 13 & 65 \\
\hline 6 to 10 & 03 & 15 & 04 & 20 \\
\hline 11 to 15 & 04 & 20 & 01 & 5 \\
\hline$>15$ & 03 & 15 & 01 & 5 \\
\hline Not answered & 00 & - & 01 & 5 \\
\hline \multicolumn{5}{|l|}{ Other paid activity } \\
\hline Yes & 03 & 15 & 06 & 30 \\
\hline No & 17 & 85 & 14 & 70 \\
\hline \multicolumn{5}{|l|}{ Post-graduation } \\
\hline Complete & 07 & 35 & 09 & 45 \\
\hline Incomplete & 05 & 25 & 03 & 15 \\
\hline Not answered & 08 & 40 & 08 & 40 \\
\hline
\end{tabular}

Table 1 shows the predominance of the female gender, with a more significant variation in age among the interviewees and a less significant variation in relation to the time of work in the current position of practical nurse. The data disclose that $85 \%$ of the nurses do not have another employment bond beyond the one exerted in the researched hospital and that $60 \%$ are accomplishing or have accomplished a post-graduation.

The Cronbach's Alpha was calculated for each hospital $(n=20)$ and with all the sample $(n=40)$, yet still, for a better exploitation of the information, there were reliability intervals for these indices calculated through the method bootstrap and all were of a $95 \%$ reliability.

For Hospital 1, the calculated Cronbach's Alpha was 0.86 , yet for Hospital 2, the Cronbach's Alpha presented the value of 0.88 and, considering the whole sample, the result was 0.88 . In all the considered configurations, the Cronbach's Alpha presented values that indicate high internal consistency among the answers.

Figure 1 shows the factorial scores of each of the 21 questions of the instrument, after the adjustment of the factorial model with seven components, being six of structural empowerment and one of global empowerment. The factorial scores measure the correlation of the question with the component (factor) as non-observable. More specifically, the factorial score 
is the correlation that a determined question has with each of the underlying factors. Like this, it is reasonable to assume that the questions of the factor opportunity have high correlation with this factor, and so on.

The questions marked in boldface in Figure 1 correspond to the factors where they should be and the ones in italics when they were in a different factor than the expected one. The results show that the factors: opportunity, information, support and resources were correctly identified by the factorial analysis, indicating â high compliance of the questions with the components. The factor formal power presented minor identification, which means its questions did not show a high correlation with this factor; however it does not invalidate its applicability. The sixth factor, informal power, showed two of its indicator highly correlated with the theoretic component and two being in other factors. The two final questions of the questionnaire, referring to the evaluation of the component, were adequately identified as a seventh factor.

\begin{tabular}{|l|c|c|c|c|c|c|c|}
\hline Questions & F1 & F2 & F3 & F4 & F5 & F6 & F7 \\
\hline F1Q1 & $-\mathbf{0 . 9 0 9}$ & - & -0.139 & -- & -- & -- & -- \\
\hline F1Q2 & $-\mathbf{0 . 8 5 7}$ & -0.145 & -- & -0.129 & -- & -0.196 & 0.101 \\
\hline F1Q3 & $-\mathbf{0 . 5 9 0}$ & -0.269 & -- & -0.327 & 0.412 & -0.295 & -- \\
\hline F2Q1 & -- & $-\mathbf{0 . 8 2 5}$ & -0.240 & -0.211 & -- & -0.288 & -- \\
\hline F2Q2 & -0.244 & $-\mathbf{0 . 8 5 5}$ & -- & 0.162 & -0.216 & -0.115 & -- \\
\hline F2Q3 & -- & $-\mathbf{0 . 8 9 7}$ & -- & -- & -- & -- & 0.121 \\
\hline F3Q1 & -- & -0.329 & $-\mathbf{0 . 8 3 9}$ & -0.144 & -- & 0.101 & -- \\
\hline F3Q2 & -- & -- & $-\mathbf{0 . 8 9 1}$ & -- & -- & -0.107 & 0.175 \\
\hline F3Q3 & -0.108 & 0.138 & $-\mathbf{0 . 8 0 2}$ & -0.159 & -0.367 & -- & 0.126 \\
\hline F4Q1 & -- & -- & -- & -0.864 & -0.113 & -0.114 & -0.154 \\
\hline F4Q2 & -0.134 & -- & -0.181 & -0.896 & -- & -- & 0.130 \\
\hline F4Q3 & -- & 0.132 & -0.218 & -0.479 & -0.722 & -0.199 & -- \\
\hline F5Q1 & -0.405 & -0.536 & -0.205 & -0.373 & -0.282 & -- & -- \\
\hline F5Q2 & -- & -- & -0.425 & -0.691 & $-\mathbf{0 . 1 3 0}$ & -0.200 & 0.233 \\
\hline F5Q3 & -- & -0.358 & -0.458 & -0.419 & $-\mathbf{0 . 3 5 1}$ & -0.152 & 0.394 \\
\hline F6Q1 & -- & -0.194 & -- & -- & -0.225 & $-\mathbf{0 . 8 9 3}$ & 0.114 \\
\hline F6Q2 & -0.392 & -- & -0.542 & -0.105 & -0.185 & $-\mathbf{0 . 4 1 5}$ & 0.287 \\
\hline F6Q3 & -0.102 & -0.384 & -0.191 & -- & -0.706 & $-\mathbf{0 . 1 0 8}$ & 0.170 \\
\hline F6Q4 & -0.333 & -- & -- & -0.184 & -- & $-\mathbf{0 . 8 4 3}$ & -- \\
\hline D1 & -- & -- & -0.284 & -- & -- & -- & $\mathbf{0 . 8 8 5}$ \\
\hline D2 & -- & -- & -- & -- & -- & $\mathbf{0 . 9 3 7}$ \\
\hline
\end{tabular}

Figure 1 - Results of the adjustment of the factorial analysis model in the questionnaire CET- II. Curitiba, PR, Brazil, 2009

\section{Discussion}

The CET-II questionnaire obtained a Cronbach's Alpha of 0.88 , representing high internal consistency among the answers. This result resembles the three Laschinger(15) researches. In study 1 , the Cronbach's Alpha was 0.87 ; in study $2: 0.82$, and in study $3: 0.88$. These initial researches already indicated the validity of the instrument.

In a study with CWEQ-II, whose objective was to evaluate the management capacity of a group of managing and practical nurses, the Cronbach's Alpha was $0.91^{(16)}$; in another one, authors examined the relation between the perception of 257 nurses of critical areas among empowerment by means of CWEQ-II and the Anticipated Turnover Scale, the result of the Alpha was
$0.82^{(17)}$; on empowerment and satisfaction of teaching nurses, the alpha was $0.84^{(18)}$. Such results indicate lower values than the obtained ones in this research.

On the occasion of the modification of the original Conditions of Work Effectiveness Questionnaire (CWEQ) to the CWEQ-II, the authors, based on factorial analysis, validated the questionnaire, which supplied evidence of a high correlation of the global empowerment measure and the validity of the component with an index of $0.99^{(17)}$, what shows proximity to the data obtained in Figure 4 of 0.88 for formal power and 0.93 for informal power.

The results indicate that although the factor formal power (F5Q1, F5Q2, F5Q3) not being identified correctly, all the others had â good correspondence between the factorial analysis and the theoretical components of the 
questionnaire, what indicates that this questionnaire is really qualified to measure such not observed latent variables. The results of the factorial analysis yet indicate that $83.5 \%$ of the information contained in the 21 questions can be summarized through the latent factors, what is considered sufficiently satisfactory.

Instruments that measure the structural power of nurses in health institutions are rare, if not absent in national literature, however, other instruments developed in foreign literature are amply translated and validated for usage in Brazil, generating knowledge about different areas of nurse performance ${ }^{(19-25)}$.

\section{Conclusion}

Facing the results of the Cronbach' Alpha of 0.88 , reliability intervals of $95 \%$ and satisfactory results of the factorial analysis, the questionnaire CET-II obtained scores that are similar to the originals of Laschinger and other authors, showing the validity of the transcultural adaptation of the instrument for usage in the Portuguese language.

The process of transcultural adaptation and validation of the components of the Portuguese version of the questionnaire is our first investigative action in a future project as its validation represents another resource at the disposal of the researchers who aim at better understanding the empowerment of nurses and its relation with the organizations and the directive groups of health institutions.

The application of the instrument will be useful for studying the work of the nurse under different circumstances, with regard to the conditions of structural, global and psychological empowerment. The results of the CET-II usage may result in an opportunity for reorganization of the work conditions of the nurse in the organization.

Instruments with these characteristics are incipient in literature, so exploring the subject was a challenge, considering its relevance for a deeper look into the ample and complex work of the nurse. With this in mind, the instrument in the Portuguese version could be an additional management tool.

\section{References}

1. Carvalho SR. Os múltiplos sentidos da categoria "empowerment" no projeto de Promoção à Saúde. Cad Saúde Pública. [periódico na Internet]. 2004 [acesso 28 abr 2011]; 20(4):1088-95. Disponível em: http:// www.scielosp.org/pdf/csp/v20n4/24.pdf.
2. Vasconcelos E. O poder que brota da dor e da opressão: empowerment, sua história, teorias e estratégias. Paulus: Rio de Janeiro; 2004.

3. Laschinger HKS. A theoretical approach to studying work empowerment in nursing: a review of studies testing Kanter's theory of structural power in organizations. Nurs Admin Q. 1996; 20:25-41.

4. Kanter R. Men and women of the corporation. 2 ed. New York: Basic Books; 1993.

5. Bernardino E, Felli VEA. Knowledge and power necessary to reconstruct nursing after management changes at a teaching hospital. Rev. Latino-Am. Enfermagem. 2008;16(6): 96-102.

6. Bernardino E. Gestão do trabalho em saúde, visibilidade social e relações de poder. In: Anais do 62. Congresso Brasileiro de Enfermagem; 2010; Florianópolis, SC. Brasília: Associação Brasileira de Enfermagem; 2010.

7. Santos AS. Reflexos da história das políticas públicas e de gestão em atenção primária: desdobramentos para a enfermagem. In: Santos AS, Miranda SMRC, organizadores. A enfermagem na gestão primária à saúde. Barueri (SP): Manole; 2007.

8. Chandler GE. The relationship of nursing work environment to empowerment and powerlessness. [tese doutorado]. Utah (EUA): College of Nursing, University of Utah; 1986.

9. Laschinger HKS, Finegan JE, Shamian J, Wilk P. Impact of structural and psychological empowerment on job strain in nursing work settings: expanding Kanter's Model. J Nurs Admin. 2001;31(5):260-72.

10. Guillemin F, Bombardier C, Beaton D. Crosscultural adaptation of health-related quality of life measures: literature review and proposed guidelines. J Clin Epidemiol. 1993;46(12):1417-32.

11. Pasquali L. Psicometria: teoria e aplicações. Brasília: Universidade de Brasília; 1997.

12. Siegel S. Estatística não paramétrica: para ciências do comportamento. São Paulo: Mc Graw-Hill; 1975.

13. Nunnally JC. Psychometric theory. 2 ed. New York: McGraw-Hill; 1978.

14. Pereira JCR. Análise de dados qualitativos: estratégias metodológicas para as ciências da saúde, humanas e sociais. São Paulo: EDUSP; 1999.

15. Laschinger HKS, Almost J, Tuer-Hodes JAD. Workplace empowerment and magnet hospital characteristics. JONA. 2003; 33(7/8):410-22.

16. Regan LC, Rodrigues L. Nurse empowerment from a middle-management perspective: nurse managers and assistant nurse managers workplace empowerment views. Permanent J. 2011;15(1):101-7. 
17. Hauck A, Griffin MTQ, Fitzpatrick JJ. Structural empowerment and anticipated turnover among critical care nurses. J Nurs Manage. 2011;19(2):269-76.

18. Baker SL, Fitzpatrick J], Griffin MTQ. Empowerment and satisfaction in associate degree nurse educators. Nurs Educ Perpect. 2011;32(4):234-9.

19. Mininel VA, Felli VEA, Loisel P, Marziale MHP. Crosscultural adaptation of the Work Disability Diagnosis Interview (WoDDI) for the Brazilian context. Rev. LatinoAm. Enfermagem. jan-fev 2012;20(1):27-34.

20. Schmidt DRC, Dantas RAS. Analysis of validity and reliability of the adapted portuguese version of Antonovsky's Sense of Coherence Questionnaire among nursing professionals. Rev. Latino-Am. Enfermagem. jan-fev 2011;19(1):42-9.

21. Rabelo ER, Mantovani VM, Aliti GB, Domingues F. Cross-cultural adaptation and validation of a disease knowledge and self-care questionnaire for a Brazilian sample of heart failure patients. Rev. Latino-Am. Enfermagem. mar-abr 2011;19(2):277-84.

22. Giordano PCM, Alexandre NMC, Rodrigues RCM, Coluci MZO. The Pain Disability Questionnaire: um estudo de confiabilidade e validade. Rev. Latino-Am. Enfermagem. jan-fev 2012;20(1):76-83.

23. Feijó MK, Ávila CW, Souza EN, Jaarsma T, Rabelo ER, Feijó $\mathrm{MK}$, et al. Cross-cultural adaptation and validation of the European Heart Failure Self-care Behavior Scale for Brazilian Portuguese. Rev. Latino-Am. Enfermagem. set-out 2012;20(5):988-96.

24. Diaz Heredia LP, Munoz Sánchez AI, Vargas D. Reliability and validity of spirituality questionnaire by Parsian and Dunning in the Spanish version. Rev. LatinoAm. Enfermagem. maio-jun 2012;20(3):559-66.

25. Carvalho REFL, Cassiani SHB. Cross-cultural adaptation of the Safety Attitudes Questionnaire - Short Form 2006 for Brazil. Rev. Latino-Am. Enfermagem. maio-jun 2012;20(3):575-82. 